\title{
Resistance \& permanence of green urban systems in the Globalization Age
}

\author{
Rita Occhiuto \\ Faculté d'Architecture. Université de Liège, Liège, Belgium \\ E-mail: r.occhiuto@ulg.ac.be
}

\begin{abstract}
The rapid transformation and the trivialization of landscapes in Wallonia (BE), require reformulating tools and objectives of morphological studies. Built fabrics and landscapes show the effects of abandoning or losing interest in the interrelations between natural and human actions. This contribution focuses on studies of cities and territories that have ceased to be the object of spatial policies attentive to the relationship between the need to live, maintain or care for green or natural spaces. After the systematic reduction of urban environments to simple green covers, morphological reading allows the recognition of traces of park systems or green infrastructures, whose communities often do not remember. The research's focus has shifted from the building to the green space structure. This displacement of interest makes it possible to find commons cultures that have acted on the territory of Liège (industrial city) on the one hand, through the building's extension and on the other hand, through the project of forests, walks, squares, parks and public gardens. Now, these fragmented places become the main resource for reorganizing natural and human systems in order to offer new - social and spatial - coherence for tomorrow. Thus the historical green systems become a strong structuring link which serves to seek new dialectics of balance between existing fabrics and green systems. This system's regeneration stands, on the one hand, to the hybridization of materials - water, green and buildings - and, on the other hand, to the physical and mental memory of the inhabited environments that populations keep. Green systems impose themselves as powerful vectors for the construction of new socio-spatial balances of cities and territories of globalization, as in the study case for the landscape systems in Liège and for the water and landscapes infrastructure in Chaudfontaine.
\end{abstract}

Keywords: Public space, park system, green and water infrastructure, morphological green writings, landscape memory.

\section{Introduction}

The critique of the city and the territory of globalization developed from the notion of the green space system allow to question the role of these places in their cyclical emergence and diffusion in contemporary urban policies. Planning rediscovers the environment through the infrastructure vision. However, it reduces the landscape aspects to surfaces and natural environments to corridors composed of an undifferentiated green that has already been ironically called "green carpet" (Hooftmann, 2007). This brings us back to the images of a modernity dominated by a surging force that engulfs and smoothes: the green flow, a minimalist turf that infiltrates all the interstices of cities and landscapes reduced to disintegrated bodies.

Globalization's topic is an opportunity for resistance approach against the call of new sirens of the functional layout which, by reusing the term of green space, still impose rhythms and paradigms of thoughts blindly 
subjugated to the economy and the technology. Terminological re-borrowing is a game that plays a major role in the logic of reaffirming globalization. Indeed, false new concepts are re-introduced with adaptive adjectival phrases that transform them in designations, such as social economy, green infrastructure, environmental technology and others, without any substantial change in their modes of action or in the consideration of materials or in the ability to offer adapted solutions. We are witnessing the resurgence of slogans which remain tools of smoothing diversity in favor of strategies that are insinuated at the local level to dissolve meshes, woven in time, and weaken the thick physical and mental relationships that characterize the places of life. We want to emphasize the urgency to return to the meaning, origin and identity of the green space in the city, in order to make it a critical tool of resistance to contemporary conceptual pressures based on terms whose meanings are completely reversed and standardized.

Moreover, if green space is still a form of a natural system in the city, what about geomorphological conditions or human reinterpretations integrated in the form of various artifacts which carry the aesthetics of new types of Third Nature? The 21th century, beginning under the aegis of ecology, seems to offer the same questions as the hygienist 19th century, but in the denial of history, time and the process of sedimentation of places dispossessed of bodily experience and spatial perception. It is the loss of these qualitative dimensions and the risks that this contribution is intended to testify through the analysis of two cases of studies concerning the Walloon territories in Belgium: the cities of Liège and Chaudfontaine.

\section{Methodology}

The green space in Wallonia (Belgium) is a topic that questions the process of mutating inhabited environments. However, it remains little studied, as there is still little interest in the readings of its origins, traits and modes of formation. It remains to be understood whether the green space designates places that have been formed spontaneously or as a result of punctual projects. Often used as a functional strategy, urban spaces should be considered as the visible face of an unstable relationship that makes it possible to understand the feeling of belonging of the inhabitants and their capacity to appropriate the places to insert their prospective visions through urban and landscape projects. Starting from this lack of in-depth knowledge, we believe that from the notion of green space we must understand the role and the ideologies that enabled it to embody the urban policies of the 19th century. But it is also necessary to understand the reasons for its loss of influence over time and to establish the opportunities that this subject still offers to reconstitute the spatial, perceptual and environmental chains which our living environments are cruelly lacking today. It is with this objective that our method refers to the natural and human morphologies as well as to the complex writings of nature and culture of which the system of the green spaces can still constitute today an indicator of great interest.

The methodology adopted relates to the comparative reading of historical maps rich in transformation's marks, which can be made to reappear in order to render thickness and significance to territories, reduced to the state of functional objects, from which they do not remains more as a sign of cartographic distinction, than the differentiation of colors designating, in a zoning logic, their destination. The interpretive reading of the maps and the diachronic analysis carried out on the basis of these documents are complemented by the in situ observation of these sites which are now reduced to zones of activity or to free surfaces, however, submitted to strong land pressure. On the basis of the process of reading reengaged, on the map and in situ, we establish new interpretations, even stories or new writings which serve to render voice, visibility and recognition to the ordinary and especially to multiple neglected existing spaces considered such as residues from functional cutting. Today these spaces, without names and without identities, are the weakest places of the territory and the most difficult to defend against the indiscriminate occupation of the soil resource.

As it was practiced in England in the 19th 


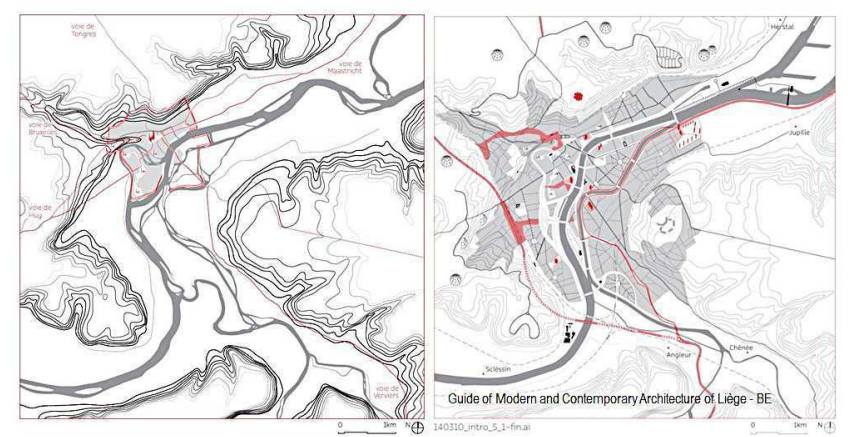

Figure 1.

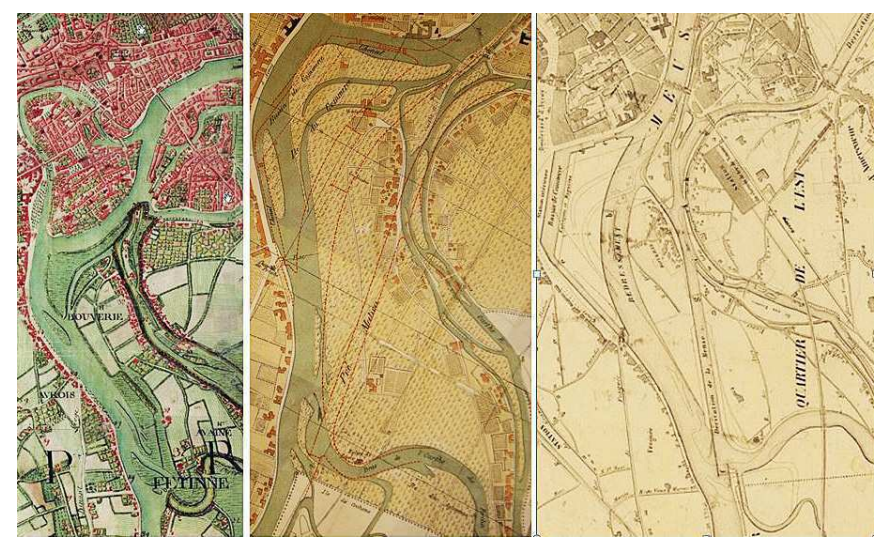

Figure 2.

century, it is necessary to reverse the reading of these non-places in order to recognize them as common places. This reversal represents the interactive part of a finalized method of making a new look emerge, capable of transforming the territorial divisions into systems of writing bearing signifiers and intentions of projects to be re-appropriated and recycled as if they were materials whose economy, utility and lost meanings must be re-learned. Thus, morphological elements will be used less to propose a new constructive logic than to reconstruct the chains of broken signifiers $($ Eco, 1972). In this way, the generic green spaces, which are specific to the era of globalization, can claim to be recognized again as materials for re-aligning the territory rather than being relegated to the state of residues of a voracious economic division into consumption space.

The originality of the method used to practice spatial reassembly is due, on the one hand, to the narrative and significant dimension of the re-reading process and, on the other hand, to the notion of green space in itself. Indeed, from this type of space, it is possible to reconstruct several types of systems in order to reorganize the materials of the territory. The green space, thus, imposes itself as an inexhaustible resource to reinvent new logics of interrelations between parts of cities and territories. This gives the design process a more open dialectical and interdisciplinary character that allows for more flexible relationships between the different components of the same system. Green spaces become catalysts for reinventing the project's modes and temporalities: it is no longer a fixed formal solution, but rather sketches or scenarios that impose themselves as flexible and adaptable hypotheses. The green space is thus a strategy for rethinking the city and the territory as it is at the same time a material, a spatial category and an open system perfectly suited to multiple readings and trans-scalar interpretations from which it is possible to cause the emergence of adaptable logics to the continual mutations of the environments. 


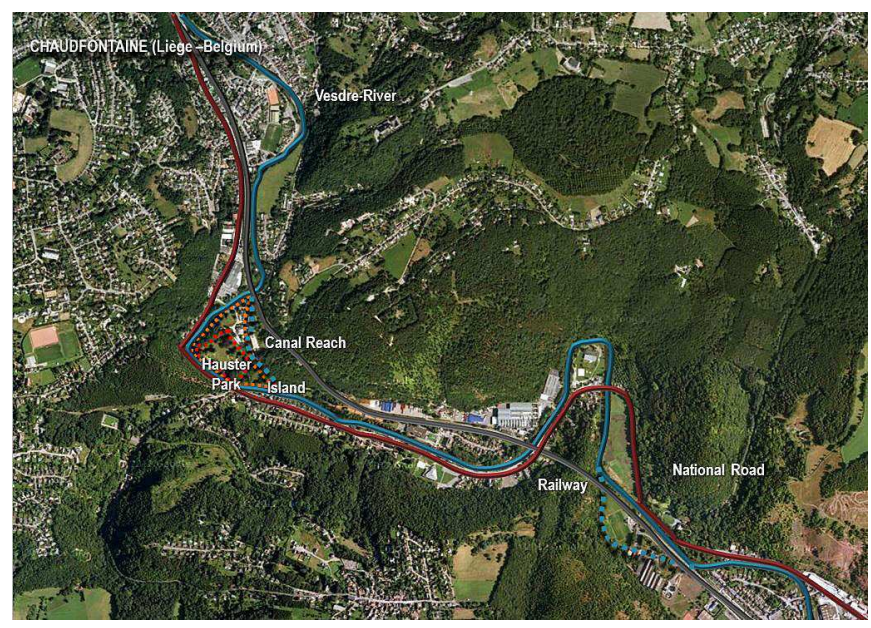

Figure 3.

\section{Context, materials and discussion}

The two chosen studies' cases concern cities of different sizes which, however, have common characteristics: urban valley sites; strong links with the waterways that cross them and feed them; the 19th century voluntarist development projects that produced high quality green spaces systems, followed in the 20th century by ignorant actions of landscape intentions or the embellishment concretized in the past. For several reasons, these cities have been the basis of projects which have profoundly modified the physical configurations of places: in Liège, the secondary waterways are drained and the main river-course is changed by inscribing a new network of public spaces, in order to assume the project of the bourgeoisie; in Chaudfontaine, on the one hand, the thermal qualities of the water sources are exploited and, on the other hand, the river is used as a driving force through the creation of channels which feed the industries, and enhance the residences and the gardens. Both take advantage of the geomorphological characteristics of places with vagabond and capricious waters in order to stabilize the lands and to channel the rivers, while building ambitious projects of architecture and nature. However, the 20th century mutations produced in both cases an over-investment of the valleys with a progressive loss of the traces which constituted the visible part of projects of parks and gardens. To this material loss of the marks graved on the ground and of the vegetation's persistence have to be added the spatiality's'

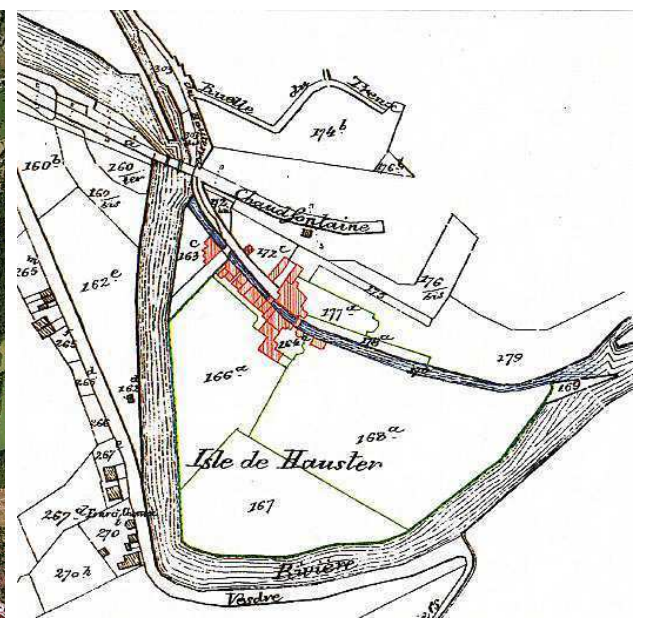

Figure 4.

and intentions' forgetting of an era when the hydraulic project of domination of the rivers was often accompanied by a spatial qualification based on informed choices of plant forms and species. Morphological reading applied to the natural contexts of origins and the progressive forms of inscription of human appropriations allowed making visible the logics or the reasons (Berque, 1993) of all the stages of transformation of places. Indeed, the nature of the green space has allowed to offer open spatial solutions, suggesting appropriations of multiple places and for this reason, particularly adapted to play a major role in the process of restoration of meaning to unmarked and degraded territories, henceforth inscribed in the imagination of the populations as lost spaces, or even non-existent or sites reduced to the state of waste.

a. The Boverie park, a green urban system of the 19th century in Liège.

The study of public parks' system, set up in the 19th century as part of the remediation and modernization of the fabrics of the old city, is the basis of two different research projects: on the one hand, the analysis of the urban growth published in the guide of modern and contemporary architecture of Liège (LabVTP, 2014) and on the other hand, the international competition for the extension of the Museum of Boverie (Ricciotti, Hautecler, Occhiuto, 2011). In both cases, the study of morphological mutations was not the object of the request, 
but it was a prerequisite for research, which is part of the methodology adopted by the LabVTP "City-Territory-Landscape" (ULG). On the one hand, this approach is part of the classical logic of the morphological studies of the Italian school (Muratori-Caniggia) and, on the other hand, in the cultural movement of French landscapers through the thought of Michel Desvigne who defends the idea of "landscape as a prerequisite" (Desvigne,2002). Indeed, the two approaches start from the fine study of the natural or geomorphological conditions that found, favor and suggest the exploitation and the continuous transformation of the territory. These converging glances recognize the role of geographical features as the generator of all types of human inscription, ranging from road and parceled cuttings of fields and suburbs to the more complex forms of large urban agglomerations. If the landscapes are the revealing supports of these multiple types of traces, all the artifacts due to human action are the expression of the close interrelations existing between man and nature. The originality of the artifact that today constitutes the city of Liège is precisely the intense dialectic maintained between natural and human actions: what allows us to call it a landscape-city. Here mutations have followed a slow process of human domination on the natural forces. Indeed, the original geomorphological site, with the feature of an archipelago, has been gradually converted into a large valley marked by the Meuse and its tributaries completely channeled and/or dried. Today, the landscape-city of yesteryear has physically and mentally disappeared, just like the titanic work of landscape rewriting done in the 19th century through hydraulic drainage works. Today, there is hardly any trace left in the collective memory.

The research is thus based on a work of reading and measuring of the pre-existing traces mainly constituted by numerous water lines. From every historical period there remain the marks of the effects produced by water on the earth. These traces are inscribed or incised on the body of the original landscape and remain legible, even though the different layers of material brought by the advancement of the urban form, at each backfill of water lines or at any time when the need for building land has led to the redesign of the geography of the site. From these superimposed readings, the centrality of the notion of movement emerges in a tangible way and is adopted as an indispensable parameter for understanding, thinking and reconsidering the architectural and landscape space. Its importance is confirmed by Vittorio Gregotti who defines territory as an "acted matter" to be linked to the continuous human need to "reinvent new geographies"(1986). These words resonate in Giuseppe Dematteis's concept of "implicit project" (1995), which recognizes the existence of internal dynamics within the territory (natural and human) and anticipates, on the one hand, the theme of the imaginary, understood as a resource and the principles of co-action, interrelation and shared perception, as defined in the Landscape definition, established by the European Landscape Convention (CEP-ELC, 2000). The knowledge of the substrate on which the system of green spaces is inscribed, generated by the park of Boverie, restores the significance to the project. Indeed, the conceptualization of the states reached by the landscape materials allows not only to understand the deep meaning of the movement in the original character of the Meuse valley, but also offers the opportunity to reconsider the cultural and symbolic importance of the projects of green systems for the city and its inhabitants in the 19th century.

From the comparative study of historical maps clearly emerges that the waterways were the main resource for redesigning the city and its public spaces. Moreover, they constitute wide corridors that welcome new tree-lined boulevards. Apart from a few strategic nodal sites, usually located on the banks of the Meuse (Poste, Coronmeuse, etc.) or close to the collegiate (Hautecler, 2017), the city did not have large planned public spaces. The nineteenth century marked the beginning of an era of equipment and modernization that made both new fabrics through the creation of urban extensions (Fragnée, St. Léonard, Bressoux, Droixhe, Longdoz) and types of Parks and public gardens. This renewal project is closely linked to the development of the industry, supported by a dense rail network, but also by the adaptation 

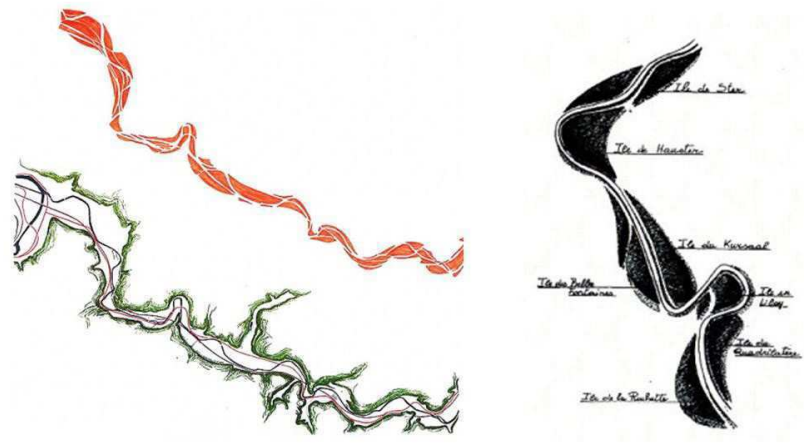

Figure 5.

of existing waterways to the new needs of river transport. From 1850 onwards, the project of the waterways became a major challenge to make one of the most important cities in the Middle Ages, a center that remained attractive in the modern era. To this end, the course of the Meuse is redesigned and the arms of the Sauvenière and the Ourthe are gradually dried up. From this water management operation for the redesign of the Isle and commercial development along the river flows, follows the project of the Derivation Canal, which collects the waters scattered on the right bank, and the modification of the course of the Meuse, regulated, smoothed and controlled flow. But what distinguishes this project is the political determination, the technical solidity and the existence of a bourgeois culture carrying economic and cultural valorization objectives. The system of green spaces, starting with the Boverie, is taking shape at that time thanks to the mastery of hydraulic techniques and in response to the growing needs of commercial exchanges linked to industrial development.

By comparing the historical maps, it appears that the site of the inscription of the park of the Boverie occupies former floodplains and meadows intended for rural walks out of town. Several documents testify to this moist campaign atmosphere. But maps of Blonden and Kummer reflect on the ancient geography of the places a precise geometric trace that corresponds to the project of formation of this thin strip of land that divides the waters of the Meuse from those of the Ourthe to the southern entrance of Liège. Between the straight line of the waters of the Derivation and the stretched arch which marks the western shore of the land, remains an artificial island on which will be implanted the "Garden of Acclimation" and the "Boverie Park". On the island, the traces of the old parcel, conditioned by the flow of water coming from the arms of the Ourthe, create an oblique line that gives shape to the urban block built on the "Rue du Parc". This line will turn into a green dike culminating on a hill that marks the articulation between the two green spaces. The Park, reworked several times, is the site of development of the Exposition of 1905. Of this project remain some buildings, but especially an English garden composition. At this time, the green spaces are composed by the Boverie and the quays which, on the Meuse they are connected to the development of the Fragnée district, while on the Derivation they are deployed in the form of a linear garden on which have been grafted the neighborhoods of St Vincent, Fétinne and Vennes. Thus the park maintains a centrality which still has a strong landscape character as well as beautiful banks on the Derivation and on the Meuse. To the left bank, the system of green spaces created in the 19th century gradually expanded through the composition of the terraced gardens (points of articulation with the linear system of the banks on the Meuse), the park of Avroy and the Botanical Garden (Center of gravity of a new neighborhood of bourgeois housing). The network is developing by creating new districts, some linked to the presence of university buildings, acting as real builders of the city and its green spaces. In these places of greater dimension are added the linear structures formerly corresponding to the streams. These sites, of variable width, as in the case of the boulevard d'Avroy and the Terrasses, are 
systematically redesigned as green walks composed by tree-lined malls. Thus, all of these new urban layouts, mostly constituted by soil removed from the river's grip, gradually form a green structure that penetrates the entire city, redefines it, and qualifies it by conveying new ways of life linked to the system of walking, strolling and leasure with sports on lawn and water. It is only from the 1960s that these places have been the scene of an overdensification and sudden modification of urban landscapes. The project of a vast network of expressways modifies the rhythms of the uses and at the stroll follows the speed and the distanciation from the edge of the river, linked with a growing oblivion of the values and the spatial and landscape qualities of this green heart which seemed to float on the water. The Parc de la Boverie is still the center of a system of green spaces to rediscover today. This study, by making the reappearing of the palimpsest of nature and architecture constituted by the park, made it possible to question the opinions on this type of space by opening to a probable inversion of the policy of exploitation of the system of green spaces.

b. Park Hauster as a part of the island system on the Vesdre in Chaudfontaine

In the case of Chaudfontaine, too, the question asked did not concern the city's green space system, but only a grassed area which once was only part of a larger park. The trans-scalar reading made it possible to take the necessary distanciation to resituate this small piece of territory within a wider system, constituted by the narrow valley of the Vesdre, following the rhythm of several meanders. The land of Hauster, after the digging of a canal of exploitation of the waters like driving force for the industry, became an artificial island which punctuates the course of the river. The raised land was shaped to host the industrial building, the manor house and the Englishstyle leisure park. This property has been progressively deconstructed until the last stage of unbundling of the parts of the building, constituted by the separation between the residence and its garden. The project of closing this residual green space, operating however as a public park, is at the origin of a re-reading of the places, in situ and through the historical maps, from which we were able to replace this fragment of territory in its own landscape and urban system. Indeed, this land, which seemed to be a site isolated from the rest, like an island, proved to be an important part of a territorial system developped between two great meanders formed by the river. By re-reading the territory as an artifact mainly drawn by lines and islands, we were able to understand that the natural system of the valley, formed by the course of the river, accompanied by its plains and hills, was transformed by the addition of lines of canals, roads and railways. These marked the territory by superposition, by practicing engravings that transformed each meander or other land division into islands, showing the effects of an infrastructure development which has completely fragmented today the city and its properties, such as Hauster where the castle and the park were split. Faced with this situation, the reading of the maps, combined with a reassembly of the tesserae of this territory, made it possible to present the Hauster terrain as one of the plains forming part of a de-structured river system, to be reconstructed starting from the creation of a system of collaborative public spaces extended along the valley territory of the town of Chaufontaine. Thus, as in a "Mobile" of Calder, the terrain of Hauster is re-inscribed in a system dealing with the course of the Vesdre which supports a series of green spaces whose relations and equilibriums must be restored. From this imagined concept, the public spaces system becomes obvious again, and Hauster's project becomes the start of a more ambitious program which will take a longer time to requalify several spaces of this revealed system, as well as the water and river spaces, which have been relatively little considered up to this point.

\section{Conclusion}

In both cases, the re-reading of the geomorphological conditions that allowed and even suggested the project, has revealed to be an indispensable step for the reconstruction 
of the knowledge in order to give to the green spaces their deepest meaning. By overcoming the state of being just places of natural aesthetics in the city, the new green spaces may re-acquire corporeity, naturalness, temporality, systemic equilibrium and open a new era for links' reconstruction between the inhabitants and the natural spaces offered to them by projects for new sustainable space systems. The descriptive and narrative dimension of this approach is not only a method for deepening the knowledge of the studied places. But it is also a necessity in order to restitute to the inhabited and transformed places the possibility of telling stories, encounters and natural and human contingencies that have changed them in what they have become today. The narrative dimension thus becomes a tool for the research and for the understanding of the cultural intentions that have transformed places. But at the same time, it allows to transform each place into a moment of learning concerning the collective culture that impresses all inhabited territories. Green spaces, through this rediscovery of the links with the geographies of the sites, can be re-read as a major element of the urban and landscape composition, since they represent a jewel case or a spatial condensation which contains the materials of the natural systems but also the cultural interpretation forms that the inhabitants have given and still give to all landscape that they live and experiment from the inside.

In conclusion, what has today become an inconsistent green carpet is actually one of the main vectors of transformation that allows to reacquire environmental consciousness, the perceptual depth and the renewal of cultures and aesthetics whose green spaces are the guardians, since their entry in town as public urban parks. The desire to give to the system of green spaces a qualitative value, focused on perception and project aspects of living space, today becomes an act of resistance in opposition to urban policies that have reduced this type of place at the status of "Empty boxes" no longer allowing any form of re-appropriation. Thus Project, Material, Time, Relationship and Narrative can constitute the basic elements of a paradigm of resistance to spatial and functional smoothing to which green space has been subjected in the age of globalization.

\section{References}

Caniggia, G., Maffei, G.,(1979), 'Composizione architettonica e tipologia edilizia.Lettura dell'edilizia di base', ed. Marsilio, (Venezia)

Dematteis, G., (1995), 'Progetto implicito. Il contributo della geografia umana alle scienze del territorio', ed. Franco Angeli, (Milano)

Desvigne, M., (2001), 'La fabrication pragmatique du territoire', in Penser la ville par le paysage, dir. Masboungi, A., ed. de la Villette (Paris), pp.52-59

Desvigne, M., (2009), 'Natures Intermédiaires', ed. Birkhauser Verlag AG, (Bâle)

Gregotti, V., (1986), 'Il disegno degli spazi aperti', in Casabella, ${ }^{\circ} 527$, pp.2-3

Eco, U., (1972), 'La structure absente',....

Hooftman, E., GrossMax (2007), 'Low land/high land', in PANORAMA NL-SC EUROPA, (Glasgow), pp.71-72

Masboungi, A., (2011),'Le paysage en préalable, Michel Desvigne. Grand prix de l'urbanisme 2011', éd. Paranthèses (Paris)

Occhiuto, R., (2014), 'Voyage au rythmes d'une ville-paysage', in 'Guide d'architecture moderne et contemporaine 1885-2014Liège' ed. Mardaga \& Cell.Architecture Féd. Wallonie Bruxelles. pp. 9-27 